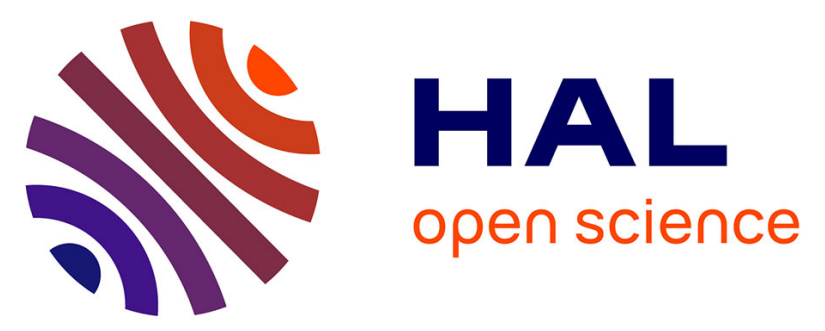

\title{
Identification of residual breast tumour localization after neo-adjuvant chemotherapy using a radioactive 125 Iodine seed
}

Y.E.A. van Riet, A.J.G. Maaskant, G.J. Creemers, L. van Warmerdam, F.H. Jansen, C.J.H. van de Velde, H.J.T. Rutten, G.A.P. Nieuwenhuijzen

\section{To cite this version:}

Y.E.A. van Riet, A.J.G. Maaskant, G.J. Creemers, L. van Warmerdam, F.H. Jansen, et al.. Identification of residual breast tumour localization after neo-adjuvant chemotherapy using a radioactive 125 Iodine seed. EJSO - European Journal of Surgical Oncology, 2010, 36 (2), pp.164. 10.1016/j.ejso.2009.10.009 . hal-00557772

\section{HAL Id: hal-00557772 \\ https://hal.science/hal-00557772}

Submitted on 20 Jan 2011

HAL is a multi-disciplinary open access archive for the deposit and dissemination of scientific research documents, whether they are published or not. The documents may come from teaching and research institutions in France or abroad, or from public or private research centers.
L'archive ouverte pluridisciplinaire HAL, est destinée au dépôt et à la diffusion de documents scientifiques de niveau recherche, publiés ou non, émanant des établissements d'enseignement et de recherche français ou étrangers, des laboratoires publics ou privés. 


\section{Accepted Manuscript}

Title: Identification of residual breast tumour localization after neo-adjuvant chemotherapy using a radioactive 125 lodine seed

Authors: Y.E.A. van Riet, A.J.G. Maaskant, G.J. Creemers, L. van Warmerdam, F.H. Jansen, C.J.H. van de Velde, H.J.T. Rutten, G.A.P. Nieuwenhuijzen

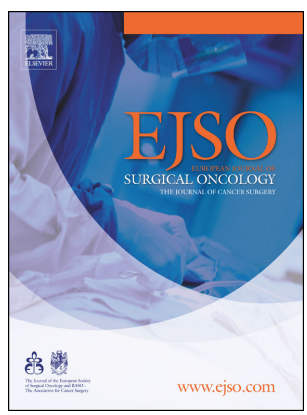

PII:

S0748-7983(09)00481-8

DOI:

10.1016/j.ejso.2009.10.009

Reference: YEJSO 2903

To appear in: European Journal of Surgical Oncology

Received Date: 10 June 2009

Revised Date: 110ctober2009

Accepted Date: 13 October 2009

Please cite this article as: van Riet YEA, Maaskant AJG, Creemers GJ, van Warmerdam L, Jansen $\mathrm{FH}$, van de Velde $\mathrm{CJH}$, Rutten HJT, Nieuwenhuijzen GAP. Identification of residual breast tumour localization after neo-adjuvant chemotherapy using a radioactive 125 lodine seed, European Journal of Surgical Oncology (2009), doi: 10.1016/j.ejso.2009.10.009

This is a PDF file of an unedited manuscript that has been accepted for publication. As a service to our customers we are providing this early version of the manuscript. The manuscript will undergo copyediting, typesetting, and review of the resulting proof before it is published in its final form. Please note that during the production process errors may be discovered which could affect the content, and all legal disclaimers that apply to the journal pertain. 


\section{Identification of residual breast tumour localization after neo-adjuvant chemotherapy using a radioactive 125 lodine seed.}

\section{Y.E.A. van Riet ${ }^{1}$, A.J.G. Maaskant ${ }^{2}$, G.J. Creemers $^{3}$, L. van Warmerdam ${ }^{4}$, F.H. Jansen ${ }^{5}$, C.J.H. van de Velde $^{6}$, H.J.T. Rutten ${ }^{7}$, G.A.P Nieuwenhuijzen ${ }^{8}$.}

${ }^{1}$ Department of Surgery, Catharina Hospital, Michelangelolaan 2,

5623 EJ Eindhoven, The Netherlands, yvonne.v.riet@catharina-ziekenhuis.nl

${ }^{2}$ Department of Surgery, Catharina Hospital, Michelangelolaan 2,

5623 EJ Eindhoven, The Netherlands, sabrina.maaskant@catharina-ziekenhuis.nl

${ }^{3}$ Department of Medical Oncology, Catharina Hospital, Michelangelolaan 2,

5623 EJ Eindhoven, The Netherlands, geert-jan.creemers@catharina-ziekenhuis.nl

${ }^{4}$ Department of Medical Oncology, Catharina Hospital, Michelangelolaan 2,

5623 EJ Eindhoven, The Netherlands, laurens.v.warmerdam@catharina-ziekenhuis.nl

${ }^{5}$ Department of Radiology, Catharina Hospital, Michelangelolaan 2,

5623 EJ Eindhoven,, The Netherlands, frits.jansen@catharina-ziekenhuis.nl

${ }^{6}$ Department of Surgery, University Hospital, Leiden, The Netherlands,

C.J.H.van_de_Velde@lumc.nl

${ }^{7}$ Department of Surgery, Catharina Hospital, Michelangelolaan 2,

5623 EJ Eindhoven, The Netherlands, harm.rutten@catharina-ziekenhuis.nl

${ }^{8}$ Department of Surgery, Catharina Hospital, Michelangelolaan 2,

5623 EJ Eindhoven, The Netherlands, grard.nieuwenhuijzen@catharina-ziekenhuis.nl 
Acknowledgements of research support

None.

\section{Corresponding Author:}

Yvonne E.A. van Riet, MD

E-mail: yvonne.v.riet@catharina-ziekenhuis.nl

Address: Catharina Hospital, Department of Surgery, PO Box 1350, 5602 ZA Eindhoven,

The Netherlands

Telephone: *31-40-2399111 Fax nr: *31-40-2443370

Disclaimers

None. 


\section{Abstract}

Introduction The use of neo-adjuvant chemotherapy has increased in the treatment of loco-regionally advanced primarily operable breast cancer. As a result of improved neo-adjuvant chemotherapy regimes the number of clinical as well as radiological responses have increased. In case of a complete response it is difficult to identify residual disease and to perform an adequate radical breast-conserving surgery. Therefore localization of the original tumour bed is mandatory. In this study we propose a novel technique with a seed containing radioactive 125 lodine $\left({ }^{125} \mathrm{I}\right)$. The ${ }^{125} \mathrm{I}$ has a half-time of 60 days and is therefore still recognisable with a gamma probe after admittance of several courses of neo-adjuvant chemotherapy.

Material and Methods In the period from July 2003 and November 2008, 47 consecutive patients had successful ${ }^{125}$ I seed localization of a breast tumour before starting neo-adjuvant chemotherapy.

$\underline{\text { Results }}$ The overall clinical response rate to neo-adjuvant chemotherapy was $100 \%$. Complete clinical response occurred in 34 patients, partial clinical response occurred in 13 patients. Complete radiological response occurred in 18 patients, partial radiological response occurred in 29 patients. The initial surgical treatment consisted of breast-conserving surgery for all 47 patients, after a mean of 170 days (range:70 - 220) after ${ }^{125}$ I seed localization. In 19 patients pathology revealed no residual tumour, 23 patients showed a partial response. Only 3 lumpectomies were irradical.

Conclusion: This study has shown that ${ }^{125}$ I seed localization is a novel and highly successful technique in localizing the tumour bed in patients who receive neo-adjuvant chemotherapy for breast cancer leading to a high percentage of radical margins in case of breast-conserving surgery.

\section{Key words:}

Breast cancer - breast-conserving surgery - neo-adjuvant chemotherapy - ${ }^{125}$ I seed localization 


\section{Introduction}

The treatment of patients with locally advanced as well as primary operable breast cancer has evolved to include neo-adjuvant chemotherapy strategies. Despite the fact that several randomized trials found little or no survival advantage comparing neo-adjuvant to adjuvant chemotherapy, neo-adjuvant chemotherapy does permit the assessment of the response of the primary tumour to a particular chemotherapy regimen(1-3) Furthermore, neo-adjuvant chemotherapy substantially reduces the size of the primary tumour in a majority of cases, thus increasing the possibility of breast-conserving surgery.(113) With the use of non-cross-resistant chemotherapy regiments, taxanes and biological response modifiers like Trastuzumab in the neo-adjuvant setting, complete clinical response rates of $65 \%$ have been documented.(4-6,11) A relative problem for breast conserving surgery after neo-adjuvant chemotherapy however is the inability to localize the residual disease in the primary tumour bed in case of complete clinical and radiological response.(3)

As long as the original tumour site is still identifiable through radiological imaging, it is possible to conduct breast-conserving surgery using standard image-guided localization techniques. The standard technique being the hookwire technique where a thin, hooked wire is radiologically guided through the skin into the lesion and the surgeon performs a wire-guided excision of the tumour. Although this technique is the current standard technique for pre-operative localization of non-palpable breast lesions there are several disadvantages.(14-15)

After neo-adjuvant chemotherapy an additional problem can be encountered if radiological imaging does not reveal any residual disease - as in case of complete radiologically response - and thus wire localization is not possible. Different therapeutical options ranging from no surgical treatment (only radiotherapy) to quadrantectomy and mastectomy are performed in this situation.(11-13) Ideally the tumour bed is marked before starting the neo-adjuvant chemotherapy, to facilitate the localization during and after the administration of the neo-adjuvant chemotherapy. Implantation - using standard image guided techniques - of a single 125 lodine $\left({ }^{125} I\right)$ labelled titanium seed before the chemotherapy into the tumour bed puts up with these prerequisites.(15-16) The 125 lodine $\left({ }^{125} I\right)$ labelled titanium seed has been described for the localisation of non palpable breast tumours. (14-17). We used the ${ }^{125}$ I seed to mark the tumour bed in patients who were planned to receive neo-adjuvant chemotherapy for breast 
cancer, and were considered to be treated with breast-conserving surgery. We document in this paper the clinical, radiological and pathologic responses to the neo-adjuvant chemotherapy as well as the feasibility of tumour retrieval and negative resection margins of the subsequent lumpectomy. 


\section{Materials and Methods}

\section{$\underline{\text { Patients }}$}

All consecutive patients between July 2003 and November 2008 that received neo-adjuvant chemotherapy treatment to down size and/or down stage T2 -T3 tumours or when axillary lymph node metastases were included in this study. In addition breast conserving therapy should be expected to be possible, before or after downsizing Patients with inflammatory, bilateral, T4 and M1-tumours were excluded from the study. Data were collected prospectively.

\section{$\underline{\text { Radioactive seed localization }}$}

After pathologic diagnosis was obtained and a neo-adjuvant treatment strategy was determined, a radioactive seed was placed into the tumour bed before start of the administration of chemotherapy. Radioactive seed localisation was carried out as described by Gray et al.(14-16) using a titanium seed containing $7 \mathrm{Mbq}$ of lodine-125 $\left({ }^{125} \mathrm{I}\right)$. This radio nuclide has a half-life of 60 days and is a $27 \mathrm{keV}$ source of gamma radiation. Because of these characteristics, ${ }^{125} \mathrm{I}$ is an excellent gamma source to use in combination with the technetium-99 (141 keV) used for sentinel lymph node biopsy. In radioactive seed localisation, the breast lesion was visualized by ultrasonography or mammography. The radioactive seed was introduced within an 18-gauche needle, guided into the lesion and using a stilette moved into the breast parenchyma centrally at the site of the lesion. Finally, the exact position of the seed was confirmed with mammography.

\section{Chemotherapy}

The neo-adjuvant chemotherapy regimen followed was either those outlined in prospective institutional trials that were open during the study period or either those according to Dutch Guidelines, and were generally doxorubicin and/or taxane based. Trastuzumab was added in patients with Her2Neu overexpression.

\section{$\underline{\text { Clinical, radiological and pathological response }}$}

Initial clinical diameter and response to chemotherapy were assessed by the oncologist and the surgeon using a caliper. Initial radiological diameter and response to chemotherapy were determined by ultrasonography, mammography and/or MRI. Response was scored using RECIST criteria (Response Evaluation Criteria in Solid Tumours)(20). Patients in whom the initial tumour could not be radiologically 
identified after neo-adjuvant chemotherapy were defined as complete radiological responders, a regression of $>30 \%$ was considered to be a partial radiological response and a tumour diameter of $>$ $20 \%$ of the initial tumour was considered to be progressive. All other patients were classified as having stable disease.

\section{Operative technique}

Breast conservation therapy was proposed to patients with a clinical post chemotherapy tumour diameter $\leq 3 \mathrm{~cm}$, but breast volume and expected cosmetic outcome were taken into account.

Operation was planned 4-6 weeks after completion of the neo adjuvant chemotherapy. The handheld gamma probe (Neoprobe 2000) was set to detect a $27 \mathrm{keV}$ source of ${ }^{125} \mathrm{I}$ and was placed over the anterior surface of the breast. The point of maximum activity marked the skin location directly overlying the seed and lesion; the gamma probe was used to guide the excision. The excised tissue volume was related to pre- chemotherapy tumour dimensions. In case of complete regression, pre-chemotherapy diameter was also taken into account when excising the tumour. Seed removal within the excision was ensured by detecting the ${ }^{125} \mathrm{I}$ source of radioactivity within the excised specimen and confirmed by detecting no ${ }^{125} \mathrm{I}$ activity remaining within the wound. All specimens were transported during the procedure to the radiology department for specimen radiology to determine the presence of the lesion and the seed and to evaluate the radiological radicality. Subsequently the breast specimen were transported to the pathology department for further examination according to the Dutch nationwide protocols. The ${ }^{125}$ I seed was removed at the pathology department, placed in a lead container and sent to the nuclear department for further storage. Axillary lymph node dissection was performed in case of evidence of malignancy prior to neo-adjuvant chemotherapy. In case of clinically negative lymph node status prior to chemotherapy either a sentinel node biopsy performed before or after starting the chemotherapy according to local or study protocols at that time. In case of a positive sentinel node an axillary node dissection was performed after the chemotherapy. 


\section{Results}

\section{Patient characteristics}

Between July 2003 and November 2008 fifty one patients received neo adjuvant chemotherapy for primarily operable breast carcinoma after intra-lesional placement of a ${ }^{125} \mathrm{I}$ seed. Three patients requested mastectomy regardless the tumour regression and one patient terminated neo-adjuvant chemotherapy before completing the cycles and subsequently received a mastectomy. These four patient were excluded from the study. Hence, 47 patients were included in this evaluation and were planned for breast-conserving therapy. The patient's characteristics are as reported in Table 1 . The pathologic diagnosis was obtained by means of ultrasound-guided or stereotactically true cut biopsy of the tumour. Receptor and Her2-neu status was retrieved from this material and shown in Table 1.

\section{Lymph node status}

After axillary ultrasound in all 47 patients and fine needle aspiration in case of suspicious lymph nodes, 25 patients appeared to be lymph node positive. A pre-chemotherapy sentinel node procedure was performed in 8 patients, five of them revealing lymph node involvement. Hence, 30 of the 47 patients (63.8\%) were lymph node positive before initiation of the neo-adjuvant chemotherapy. No further axillary treatment was conducted in the three patients with a negative sentinel node outcome. In 14 node negative patients - before starting neo-adjuvant chemotherapy - axillary staging procedures were performed after finishing systemic treatment.

\section{${ }^{125}$ I seed localization}

The pre-chemotherapy radioactive seed localization was successful in all 47 patients and position within the tumour bed was confirmed by means of mammography. No clinical complications occurred as a result of implantation of the ${ }^{125} \mathrm{I}$ seeds. On post chemotherapy imaging the ${ }^{125} \mathrm{I}$ seed was detected in all 47 patients and no migration of the seeds as compared to earlier imaging had occurred. At the time of the operation the ${ }^{125} \mathrm{I}$ seeds were in situ for a mean of 174 days (range:70 - 220, SD:42.90). Specimen radiography confirmed presence of the ${ }^{125} \mathrm{I}$ seed within the excised lump in all 47 patients.

\section{Pathological axillary response}

Axillary lymph node dissection was performed in the 30 patients proven lymph node positive before starting neo-adjuvant chemotherapy as mentioned above. There were still tumour positive lymph nodes 
on pathological investigation in 15 patients, in the other 15 patients a complete axillary response was observed. Six of the 14 node negative patients - before neo-adjuvant chemotherapy - had a sentinel node biopsy after neo-adjuvant chemotherapy, two of which appeared positive. These two patients had an axillary lymph node dissection, as well as 8 remaining patients who had no axillary staging procedure before neo-adjuvant chemotherapy. In 4 out of 8 positive lymph nodes were retrieved.

\section{Clinical, radiological and pathological response}

The clinical, radiological and pathologic post-chemotherapy regression according to the RECIST criteria is shown in Table 2. The overall clinical response rate to neo-adjuvant chemotherapy was $100 \%$. Complete clinical response occurred in 34 patients, partial clinical response occurred in 13 patients. No clinical progression occurred. The mean clinical tumour diameter decreased from 32mm (range:10-70 $\mathrm{mm}, \mathrm{SD}: 1.39$ ) at initial presentation to a mean of $5 \mathrm{~mm}$ (range:0-30mm, SD:0.80) after neo-adjuvant chemotherapy. Radiological response was determined by mammography in 7 patients, by ultrasonography in 14 patients, and in 33 patients by MRI as well. (Table 2) Complete radiological response occurred in 18 patients, partial radiological response occurred in 29 patients. Again, no radiological progression occurred. The mean radiological diameter decreased from 34mm (range:1375mm, SD:1.34) at initial presentation to 8mm (range:0-32,SD:0.87) after neo-adjuvant chemotherapy. The initial surgical treatment consisted of breast-conserving surgery for all 47 patients. Mean specimen volume was $107,25 \mathrm{~cm}^{3}$ (range:30-600 $\mathrm{cm}^{3}$, SD:124,90) and a mean weight of $38,61 \mathrm{~g}$ (range:10,80216,00g, SD:44,90) In 19 patients pathology revealed no residual tumour, 23 patients showed a partial response. In this group 8 patients showed only minimal residual tumour cells in fibrotic tissue, 14 patients had residual tumours ranging in diameter from 0.5 to $5.0 \mathrm{~cm}$ and 1 patient had multifocal tumour locations throughout the specimen. Five patients had a tumour residue as large as the initial clinical and radiological size pre-chemotherapy and were scored as stable disease. In 44 patients the excision showed pathologically radical margins. Three patients displayed irradical margins. Two showed a complete clinical and radiological response but a partial pathological response. One patient showed focal irradicality for DCIS only and was treated with an extra radiotherapy boost. The other patient underwent a secondary mastectomy. The third patient showed a partial clinical and radiological response, but a stable disease on pathological examination with malignant skin infiltration which was irradical excised 
leading to a secondary mastectomy. All patients with breast-conserving therapy received adjuvant hormonal treatment and radiotherapy according to the Dutch national guidelines. 


\section{Discussion}

In the recent years neo-adjuvant chemotherapy for locally advanced breast cancer is more used because the chemotherapy regimens are more effective and as a result of the downsizing of the tumour breast conserving surgery is possible in a majority of the patients.(1-13) Neo adjuvant endocrine therapy is even better tolerated and is thus an up coming alternative for specific groups of (postmenopausal) patients with the same intention as neo-adjuvant chemotherapy. $(18,19)$ In case of a complete clinical and/or radiological response adequate localisation for retrieving of the original tumour bed is difficult $\underline{\text { Identification of original tumour localization }}$

Different methods have been introduced to identify the original tumour localization after a radiological complete response. In the EORTC 10902 trial(1), in case of a complete clinical and radiological response tumour breast biopsy specimens were examined for the presence of microscopic residual tumour to correlate the clinical response with pathologic evaluation. As stated by Buchholz et al (3) this is a labour time intensive and complicated method. It requires careful planning and appropriate original mammograms including straight lateral views. At the University of Texas M. D. Anderson Cancer Centre, blunt metallic markers are being placed at the tumour site by ultrasonographic guidance during the course of neo-adjuvant chemotherapy in order to permanently mark the tumour bed.(8) Implantation of metallic markers has shown to be useful in marking the tumour bed (26), but this technique renders several disadvantages as well. First, to improve detection a minimum of four markers should be implanted.(26) Second, visualisation by ultrasound or mammography needs to be performed shortly before the operation. Finally, the surgeon has to operate based on the tumours' clock position, having no aid during the operation as to whether he approaches the tumour correctly. A hook-wire localisation of the metal markers can also be performed shortly before surgery, which means an additional procedure for the patient.

\section{$\underline{\text { Advantages of }{ }^{125} \text { I seed lokalization }}$}

These difficulties are overcome by implantation of $\mathrm{a}^{125} \mathrm{I}$ seed in the breast lesion before start of chemotherapy and subsequently performing a lumpectomy guided by the radioactive seed localization. The general advantages of radioactive seed localization as compared to wire localization, which is the current standard technique for non palpable lesions, are the following. $(14,17)$ Because the entry site of 
the seed is not an issue in the excision, the radiologist can choose the site that is best for precise placement without consideration of the incision site. Likewise, because the surgeon can precisely locate the seed on the skin, the incision can be made at a location closest to the lesion and thus avoid excessive dissection and tissue loss. Finally, because the radioactive seed is entirely surrounded and contained within the breast parenchyma, the possibility of displacement during confirmatory mammograms and patient transfers is being eliminated. A specific advantage in case of neo-adjuvant chemotherapy is the half life of the ${ }^{125}$ I nuclide being 60 days. As shown in our study, breast-conserving surgery of the original tumour site guided by ${ }^{125} \mathrm{I}$ seed appeared to be possible even after a mean of 170 days after localization of the tumour site prior to chemotherapy.

\section{$\underline{\text { The need of a histological confirmation of a representative excision }}$}

Van der Hage et al (1) suggested in his overview that radiological measurements should be implemented mandatory in the assessment of tumour response to have objective data to measure the degree of tumour response. Ultrasound has been shown to be an accurate method to measure the size of breast tumours (21) and has proven reliable in quantifying tumour response. $(22,23) \mathrm{MRI}$ is more frequently considered as the standard radiological imaging technique in breast cancer size assessment before, during and after neo-adjuvant chemotherapy. $(24,25)$ Although the small size of the series, superiority of MRI in predicting residual multifocal and multicentric disease has been described.(25) A negative predictive value of $67 \%$ in overestimation of tumour size is reported by Londero et al, with a potential decrease in the rate of breast conserving therapy.(24) In our study the absence of a residual mass on clinical as well as radiological examination did not exclude the possibility of a small residual viable tumour. We were able to do a thorough follow-up because of precise localization of the tumour bed, even in cases of complete radiological or pathological response. In the 34 patients with no palpable tumour residue, radiological examination showed complete regression in only 17 patients and on pathological examination 16 patients had a complete response, but 3 had stable disease. In 18 cases of complete radiological response there was no palpable mass on clinical examination but pathological examination revealed in only half of the cases a complete response. Alternatively, in some cases a residual mass on clinical or radiological examination was found to be entirely or almost completely fibrotic without pathologic evidence of viable tumour. In twenty nine patients with a partial radiological response, 9 
patients had a complete pathological response. Because of these conflicting results in clinical, radiological and pathological examination, a histological confirmation of a representative excision is mandatory.

\section{$\underline{\text { Triple negative breast cancer }}$}

In this consecutive series, neo-adjuvant chemotherapy was effective and radioactive seed localization was successfully performed in all 47 patients. In over $50 \%$ of the patients the original tumour could not be visualized or palpated after neo-adjuvant chemotherapy. This high response rate may be partly due to the great amount of triple negative breast cancers in our group. Forty-two percent were triple negative and in addition in almost $30 \%$ I of the tumours there was a Her2neu over-expression. High complete pathological response rates after neo-adjuvant chemotherapy are known for these subsets of breast cancer. $(27,28)$

\section{Pathological margin status}

In those cases of complete clinical and radiological response the ${ }^{125} \mathrm{I}$ seed was the only remaining evidence of the original tumour site. The rate of positive margins in our study was $6 \%$, which is at least comparable to the $8 \%$ rate reported by Gray et al (14-17) and is well below the rate of $50,9 \%$ for excisions utilizing wire localization that was reported by Velanovic et al.(29), both studies in non-palpable breast tumours. In a another prospective randomized trial of radioactive seed localization versus wire localization of non-palpable breast lesions, Hughes et al (30) found that radioactive seed localization resulted in a $35 \%$ relative improvement in the rate of negative margins in the first specimen and a $62 \%$ relative improvement in the rate of re-operation for positive margins.

Although this low rate of positive margin status is very promising in breast-conserving treatment after neo-adjuvant chemotherapy, thorough clinical as well as radiological follow up is mandatory. Long term results on local recurrence will influence the decision making on this treatment modality. 


\section{Conclusion}

The described technique of radioactive seed localization has shown to be safe and effective in localizing the tumour bed in patients who receive neo-adjuvant chemotherapy for breast carcinoma, solving the problem that has emerged with the increasing rate of complete responses and thus enabling the possibility of precise and long-lasting localization of the tumour bed and eventually planning for breastconserving surgery. 


\section{References}

1. van der Hage JA, van de Velde CJ, Julien JP, Tubiana-Hulin M, Vandervelden C, Duchateau L. Preoperative chemotherapy in primary operable breast cancer: results from the European Organization for Research and Treatment of Cancer Trial 10902. J Clin Oncol. 2001;19:4224-37.

2. Fisher B, Bryant J, Wolmark N, et al. Effect of preoperative chemotherapy on the outcome of women with operable breast cancer. J Clin Oncol. 1998;16:2672-85

3. Buchholz TA, Hunt KK, Whitman GJ, Sahin AA, Hortobagyi GN. Neo-adjuvant chemotherapy for breast carcinoma, multidisciplinary considerations of benefits and risks. Cancer 2003;98:1150-60.

4. Estevez LG, Gradishar WJ. Evidence based use of neo-adjuvant taxane in operable and inoperable breast cancer. Clin Cancer Res 2004;10:3249-61

5. NSABP group. The effect on primary tumor response of adding sequential Taxotere to Adriamycin and cyclophosphamide: preliminary results from NSABP Protocol B-27. Breast Cancer Res Treat. 2001;69:210-14.

6. Rouzier R, Mathieu M, Sideris L, et al. Breast-conserving surgery after neo-adjuvant anthracycline-based chemotherapy for large breast tumors. Cancer 2004;101:918-25.

7. Bonadonna G, Veronesi U, Brambilla C, et al. Primary chemotherapy to avoid mastectomy in tumors with diameters of three centimetres or more. J Natl Cancer Inst. 1990;82:1539-45.

8. Chen A, Meric-Bernstam F, Hunt KK, et al. Breast conservation after Neo-adjuvant Chemotherapy: The M.D. Anderson Cancer Experience. J Clin Onc 2004;22:2303-12

9. Chen A, Meric-Bernstam F, Hunt KK, et al. Breast conservation after Neo-adjuvant Chemotherapy. A Prognostic Index for Clinical Decision-Making. Cancer 2005;103:689-95.

10. Mauriac L, Macgrogan G, Avril A, et al. Neo-adjuvant Chemotherapy for operable breast carcinoma larger than $3 \mathrm{~cm}$ : $A$ unicentre randomized trial with a 124-month median follow-up. Annals Oncology;1999:47-52.

11. Kulkarni S, Hicks DG.HER2-positive early breast cancer and trastuzumab: a surgeon's perspective. Ann Surg Oncol. 2008 Jun;15:1677-88.

12. Mathew J, Asgeirsson KS, Cheung KL, Chan et al Neo-adjuvant chemotherapy for locally advanced breast cancer: $A$ review of the literature and future directions.. Eur J Surg Oncol. 2009; 35:113-22

13. Shenoy HG, Peter MB, Massanat YA, et al. Practical advice on clinical decision making during neoadjuvant chemotherapy for primary breast cancer. Surg Oncol 2008 Aug Epub ahead of print.

14. Gray RJ, Salud C, Nguyen K, et al. Randomized prospective evaluation of a novel technique for biopsy or lumpectomy of non-palpable breast lesions: radioactive seed versus wire localization. Ann Surg Oncol. 2001;8:711-5.

15. Gray RJ, Giuliano R, Dauway EL, Cox CE, Reintgen DS. Radioguidance for nonpalpable primary lesions and sentinel lymph node(s). Am J Surg. 2001;182:404-6. 
16. Hughes JH, Mason MC, Gray RJ et al. A multi- site validation trial of radioactive seed localization as an alternative to wire localization. Breast J, 2008; 14:153-7

17. Pavlicek W, Walton HA, Karstaedt PJ et al. Radiation safety with use of I-125 seeds for localization of non-palpable breast lesions. Acad Radiol 2006; 13:909-15

18. Valenzuela M, Julian TB Neo-adjuvant hormonal therapy. Breast J. 2008 May-Jun;14(3):279-83

19. Mieog JS, van Nes JG, van de Velde CJ. [The advantages of preoperative systemic therapy in breast cancer] Ned Tijdschr Geneeskd. 2008 Nov 15;152(46):2501-6.

20. New response evaluation. Criteria in Solid Tumours: Revised RECIST criteria (version 1.1) E.A. Eisenhauer, P. Therasse, J. Bogaerts et al. 20th EORTC-NCI-AACR Symposium Molecular Targets and Cancer Therapeutics Geneva, Switzerland (21-24 October 2008) (published Eur J Cancer 2009)

21. Bosch AM, Kessels AGH, Beets GL, et al. Pre-operative estimation of the pathological breast tumour size by physical examination, mammography and ultrasound: a prospective study on 105 invasive tumours. Eur J Radiol. 2003;48:285-92

22. Seymour MT, Moskovic EC, Walsh G, et al. Ultrasound assessment of residual abnormalities following primary chemotherapy for breast cancer. Br J Cancer 1997;76:371-76.

23. Loo CE, Teertstra HJ, Rodenhuis S, et al. Dynamic contrast-enhanced MRI for prediction of breast cancer response to neoadjuvant chemotherapy: initial results. Am J Roentgenol. 2008;191:1331-8.

24. Londero V, Bazzocchi M, Del Frate C, et al. Locally advanced breast cancer: comparison of mammography, sonography and MR imaging in evaluation of residual disease in women receiving neo-adjuvant chemotherapy. Eur Radiol 2004:14:1371-9

25. Belli $P$, Constantini M, Malpaspina $C$, et al. MRI accuracy in residual disease evaluation in breast cancer patients treated with neoadjuvant chemotherapy. Clin Radiol 2006;61:946-53.

26. Edeiken BS, Fornage BD, Bedi DG, et al. US-guided implantation of metallic markers for permanent localization of the tumor bed in patients with breast cancer who undergo preoperative chemotherapy. Radiology 1999;213:895-900.

27. Cleator S, Heller W, Coombes RC. Tripple - negative breast cancer: therapeutic options. Lancet Oncol. 2007;8:235-44

28. Liedtke C, Manzouni C, Hess KR et al. Response to neo-adjuvant therapy and long-term survival in patients with triplenegative breast cancer. J Clin Oncol. 2008;26:1275-81

29. Velanovich V, Lewis FR, Nathanson SD, et al. Comparison of mammographically guided breast biopsy techniques. Ann Surg. 1999;229:625-33.

30. Gray RJ, Pockay BA, Karstaedt PJ, Roarke MC. Radioactive seed localization of no-npalpable breast lesions is better than wire localization. Am J Surg. 2004 Oct;188:377-80. 


\section{Table 1}

Patient characteristics

\begin{tabular}{llll}
\hline Characteristics & & & \\
\hline & mean & range & SD \\
Age (yrs) & 47 & $28-68$ & 9,34 \\
Clinical diameter (mm) & 32 & $10-70$ & 1,39 \\
Radiological diameter (mm) & 34 & $13-75$ & 1,34 \\
& & & \\
Lymph node & No of patients & \\
N1 & 30 & After cytology or sn & \\
No & 17 & & \\
Histologic type & & & \\
Ductal & 42 & \\
Lobular & 3 & & \\
Undifferentiated/mixed & 2 & \\
Hormone receptor status & & & \\
ER + / PR + & 22 & & \\
ER - / PR - & 20 & & \\
ER + / PR - & 53 & & \\
Her2-Neu status & & & \\
Overexpression & & & \\
No overexpression & & & \\
\hline
\end{tabular}




\section{Table 2}

Pre- and post chemotherapy results of clinical, radiological and histological examination

\begin{tabular}{|c|c|c|c|c|c|c|}
\hline & $\begin{array}{c}\text { Clinical } \\
\text { examination }\end{array}$ & & $\begin{array}{l}\text { Rac } \\
\text { exa }\end{array}$ & $\begin{array}{l}\text { gical } \\
\text { ation }\end{array}$ & & $\begin{array}{l}\text { Histological } \\
\text { examination }\end{array}$ \\
\hline pre - chemotherapy & & Total & $\begin{array}{c}\text { Mammo } \\
n=47\end{array}$ & $\begin{array}{c}\text { US } \\
n=47\end{array}$ & $\begin{array}{l}M R I \\
n=37\end{array}$ & \\
\hline Mean size (mm) & 37 & 40 & 25 & 38 & 30 & \\
\hline Range (mm) & $10-70$ & $7-77$ & $7-60$ & $13-60$ & $10-77$ & \\
\hline \multirow[t]{2}{*}{ post-chemotherapy } & & Total & Mammo & US & $M R I$ & \\
\hline & & & $n=7$ & $n=14$ & $n=37$ & \\
\hline Mean size (mm) & 5 & 8 & 22 & 17 & 8 & \\
\hline \multirow[t]{2}{*}{ Range (mm) } & $0-30$ & $0-32$ & & $0-27$ & $0-32$ & \\
\hline & 0,80 & 0,87 & & & & \\
\hline Complete response & 34 & 18 & 4 & 4 & 18 & 19 \\
\hline Partial response & 13 & 29 & 3 & 10 & 19 & 23 \\
\hline Stable disease & & & & & & 5 \\
\hline Radical excision & & & & & & 44 \\
\hline Irradical excision & & & & & & 3 \\
\hline
\end{tabular}

